
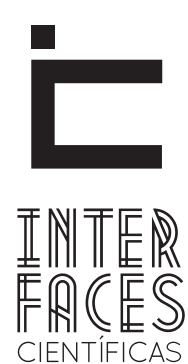

EDUCAÇÃO

ISSN IMPRESSO 2316-333X

ISSN ELETRÔNICO 2316-3828

DOI 10.17564/2316-3828.2015v3n3p33-42

\title{
INCLUSÃO ESCOLAR NA REGIÃO NORTE DO BRASIL: UM MAPEAMENTO DO ATENDIMENTO EDUCACIONAL ESPECIALIZADO NOS ESTADOS DO AMAZONAS, RONDÔNIA E PARÁ
}

Aline Roberta Tacon Dambros ${ }^{1}$

Nerli Nonato Ribeiro Mori

\section{RESUMO}

0 presente trabalho tem como objetivo traçar o perfil dos educadores e do atendimento de alunos com Necessidades Educativas Especiais (NEE) nos estados do Amazonas, Rondônia e Pará. Utilizamos no trabatho de campo a possibilidade social e dialógica de observar a realidade. Desta forma, para a viabilização da pesquisa aplicamos um questionário estruturado respondido por 118 professores das redes municipal e estadual de ensino. 0 estudo de campo nos permitiu aferir quanto à distribuição da classe docente por sexo, faixa etária, graduação inicial, pós-graduação já concluída, dependência administrativa, local de atuação profissional e escolas que possuem o serviço do Atendimento Educacional Especializado. Se considerarmos a história e os movimentos de luta pela igualdade de educação para todos, afirmamos que um grande passo já foi consolidado, a garantia de que todos os alunos com NEE tenham acesso a um ambiente escolar. Portanto, acreditamos que o novo desafio a ser alcançado pela educação inclusiva é garantir a permanência do aluno com deficiência em estrutura escolar pública.

\section{PALAVRAS-CHAVE}

Políticas Públicas. Educação Especial. Inclusão Escolar. 


\section{ABSTRACT}

This paper aims to outline the profile of educators and care of pupils with Special Educational Needs in the states of Amazonas, Rondônia and Pará used in fieldwork social and dialogic possibility of observing reality .Thus, for the feasibility of the research applied a structured questionnaire answered by 118 teachers of municipal and state schools. The field study allowed us to assess how the distribution of the teaching workforce by sex, age , initial undergraduate, graduate already completed, administrative responsibility , place of professional performance and schools that have the service of the Specialised Education Support
Services. If we consider the history and movements struggling for equal education for all, we say that a great step has been consolidated, ensuring that all pupils with Special Educational Needs have access to a school environment. Therefore, we believe that the new challenge to be achieved through inclusive education is to ensure the permanence of disabled students in public school structure.

\section{KEYWORDS}

Public Politic. Special Education. School Inclusion.

\section{RESUMEN}

Este documento tiene como objetivo trazar el perfil de los educadores y de atención de los alumnos con necesidades educativas especiales (NEE) en los estados de Amazonas, Rondonia y Pará utilizado en el trabajo de campo posibilidad social y dialógica de observar la realidad. Así, para la viabilidad de la investigación aplicada de un cuestionario estructurado contestada por 118 docentes de escuelas municipales y estatales. El estudio de campo nos permitió evaluar cómo la distribución de la fuerza laboral docente por sexo, edad, estudiante de la inicial, graduado ya completado, la responsabilidad administrativa , lugar de desempeño profesional y las escuelas que tienen el servicio de La Servicios de Apoyo a la Educación
Especializados. Si tenemos en cuenta la historia y los movimientos que luchan por la igualdad en la educación para todos, decimos que un gran paso se ha consolidado, lo que garantiza que todos los alumnos con necesidades educativas especiales tienen acceso a un ambiente escolar. Por lo tanto, creemos que el nuevo reto de ser logrado a través de la educación inclusiva es asegurar la permanencia de los estudiantes con discapacidad en la estructura de la escuela pública.

\section{PALABRAS CLAVE}

Políticas Públicas. Educación Especial. Inclusión Escolar. 


\section{INTRODUÇÃ̃O}

A Educação Especial, enquanto modalidade de ensino e organização didática que integra o sistema escolar brasileiro, tem se desenvolvido como um contínuo desafio nos ambientes: escolar, familiar, político e no social. 0 embate após a universalização da educação escolar para alunos especiais consiste, justamente, em unificar um paradigma de ensino, que agregue uma escolarização voltada para a diversidade, concomitantemente, com uma proposta educacional com qualidade científica para todos.

Nesta perspectiva, após a década de 1990 temos o início das propostas escolares com ênfase na inclusão de alunos com necessidades educativas especiais (NEE), em especial pós Lei de Diretrizes e Bases da Educação, Lei no 9394/96, a inclusão escolar, vem se estabelecendo como uma política em construção, uma vez que perpassa por inúmeros desafios de implantação efetiva, até concretizar-se um direito escolar do cidadão com deficiência.

Torna-se válido destacar que antes de um direito constitucional, promulgado pelas leis nacionais, incluir crianças com NEE no espaço escolar significa um direito para a humanização desses alunos. Acreditamos que a escola possibilita um espaço de vida coletiva e de interações grupais, nela são formados valores, normas e modo de vida. Em outras palavras, esse ambiente torna-se o local de trocas intensas de experiências e aprendizagem entre os atores que fazem parte do processo educacional.

$\mathrm{Na}$ busca pelo conhecimento dos atores que integram a inclusão escolar, este trabalho visou traçar o perfil dos educadores e do atendimento educacional especializado (AEE) nos estados do Amazonas, Rondônia e Pará. Via questionário, a pesquisa contou com a participação dos professores da região Norte que participaram do Curso de Especialização em Atendimento Educacional Especializado já concluído na Universidade Estadual de Maringá.

\section{A AÇÃO DOCENTE NO DESENVOLVIMENTO DO ALUNO COM NECESSIDADES EDUCATIVAS ESPECIAIS}

Embora a criança no decorrer de sua vida incorpore conhecimentos que the assegure experiências prévias, é a instituição escolar com a mediação do educador que permitirá a reelaboração desse conhecimento para um saber científico, bem como estabelecerá novas relações cognitivas de seu pensamento com o mundo.

De acordo com Vygotsky (2009) o desenvolvimento dos conceitos científicos apóia-se no nível de maturação dos conceitos espontâneos que, consequentemente, avançam em níveis mais elevados, conforme a criança segue em seu percurso escolar. Dessa forma, a aprendizagem escolar configura-se como fator inquestionável para o desenvolvimento intelectual do estudante.

No sentido de humanização via processo social, Leontiev (1979) destaca que o homem não nasce dotado das aquisições históricas adquiridas por gerações anteriores, mas essa apropriação acontece a partir do contato com o mundo que o rodeia, nas grandes obras da cultura humanas transmitidas socialmente.

\begin{abstract}
É evidente que a educação pode ter e tem efetivamente formas muito diversas. Na origem, nas primeiras etapas do desenvolvimento da sociedade humana, como nas crianças mais pequenas, é uma simples imitação dos atos do meio, que se opera sob o seu controle e com a sua intervenção; depois complica-se e especializa-se, tomando formas tais como o ensino e a educação escolares [...] Mas o ponto principal que deve ser bem sublinhado é que este processo deve sempre ocorrer sem o que a transmissão dos resultados do desenvolvimento sócio-histórico da humanidade nas gerações seguintes seria impossível, e impossível, consequentemente, a continuidade do progresso histórico. (LEONTIEV, 1979, p. 272).
\end{abstract}

Para se apropriar desta materialidade histórica e torná-la uma capacidade, a criança deve estar inse- 
rida em um coletivo circundante, no qual toda produção histórica seja organizada para iniciar o processo consciente de aprendizagem. Neste momento, cabe exatamente o papel social da escola, cuja atividade configura-se como meio de progressão histórica, sem ela a transmissão da história social seria impossível e, por conseguinte, inviabilizado o progresso humano.

Goulart e Mori (2009) salientam que a escola é o local de mediação cuja função é levar à criança a conscientização da linguagem. No momento de internalização dos conceitos, a mediação do professor é indispensável, uma vez que os alunos não se apropriam do significado, apenas por estar inseridos em ambientes de ensino, é essencial, que a interação com o conhecimento torne-se uma ação conscientizada, estabelecendo finalmente ações para o desenvolvimento do psiquismo da criança.

Sob esse encaminhamento, podemos conceituar que a mediação é um processo de intervenção que visa à aquisição de conhecimentos pela interação mediada pela linguagem do sujeito com o meio, como também da relação do homem com outros homens (OLIVEIRA, 1993). E o processo de internalização de particularidades sociais e culturais acontece pelas mediações, essas, praticadas na relação entre indivíduo-meio e indivíduo-indivíduo, independentes de sua cor, religião ou condições financeiras.

Por conseguinte, as ações docentes qualitativas estão diretamente ligadas ao processo de desenvolvimento do aluno com NEE. Buscamos, por meio da pesquisa realizada, extrair informações quanto ao perfil do professor, bem como, a estruturação do AEE nas referidas regiões do Norte do país.

\section{OS CAMINHOS METODOLÓGICOS DA PESQUISA DE CAMPO}

Diante de uma temática de pesquisa complexa, como a educação especial na perspectiva inclusiva, acredita- mos que o nosso desafio foi de compreender a inclusão enquanto um processo histórico-social, diretamente conectada pelo interesse hegemônico e relações sociais que compõem o objeto de análise em questão.

Os procedimentos adotados configuraram a pesquisa além de social, como também uma investigação predominantemente qualitativa. A principal característica da pesquisa qualitativa é a analise de seu objeto investigado de forma interpretativa, buscando compreender a especificidade da investigação (ALVES-MAZZOTTI e GEWANDSZNAJDER, 2002). Parte do pressuposto de que "todas as pessoas que participam da pesquisa são reconhecidas como sujeitos que elaboram conhecimentos e produzem práticas adequadas para intervir nos problemas que identificam" (CHIZZOTTI, 2000, p. 83).

Para coleta de dados aplicamos um questionário estruturado aos 118 (cento e dezoito) professores da região Norte que participaram do Curso de Especialização em Atendimento Educacional Especializado já concluído na Universidade Estadual de Maringá, com o objetivo de extrair informações quanto ao perfil do professor, bem como, a estruturação do AEE nas regiões.

Destacamos que os resultados coletados nos permitiram delinear um panorama da inclusão da região Norte em concomitância com um movimento iniciado, primeiramente, na instância nacional. Frisamos que o trabalho não exaure com a temática: inclusão escolar na região Norte do Brasil, mas acende a estudos posteriores que irão acompanhar o desdobramento da efetivação das políticas inclusivas na região.

\section{REGIÃO NORTE: PERFIL DOS PROFESSORES ATUANTES NA REDE DE ENSINO PÚBLICO DA REGIÃO NORTE}

Para identificarmos o perfil dos educadores da região Norte, utilizamos como instrumento de coleta de 
dados a aplicação de um questionário aos professores que participaram do Curso de Especialização em Atendimento Educacional Especializado, já concluído na Universidade Estadual de Maringá- PR. Considerando o tempo e os limites de uma pesquisa stricto sensu, foram delimitados os estados de Amazonas, Pará e Rondônia, para que fosse possível acompanharmos com mais detalhe os caminhos das políticas nesses estados.

\subsection{PERFIL DOS EDUCADORES}

Neste momento, categorizamos os questionários para que pudéssemos analisar qual o perfil dos educadores quanto ao perfil do professor, bem como a estruturação do AEE na região. Para apresentação dos resultados dividimos os dados em sete categorias: 1) Distribuição da classe docente por sexo; 2) Distribuição da classe docente por faixa etária; 3) Distribuição da classe docente por graduação inicial; 4) Distribuição da classe docente por pós-graduação já concluída; 5) Distribuição da classe docente por dependência administrativa; 6) Distribuição da classe docente por local de atuação; 7) Distribuição de escolas públicas que possuem o serviço do AEE.

Quanto à distribuição da classe docente por sexo a pesquisa identificou, em consonância com os resultados do Censo Escolar 2011, que a maior parte dos educadores, aproximadamente 95\%, é do sexo feminino, somente $5 \%$ do sexo masculino. Essa hegemonia tem fundamento histórico, uma vez que o movimento do magistério, iniciado pelas escolas normais, já determinavam o ofício para as mulheres. Esse fator se justifica, também, quando lidamos com o discurso de que trabalhar com alunos com necessidades educativas especiais requer uma ação mais afetiva e benevolente. Assim, por muitos anos, mesmo no interior de um movimento de mudança, são as mulheres que dedicam sua ação educacional aos alunos NEE.
Gráfico I - Distribuição da classe docente por sexo - Região Norte

\section{Sexo dos educadores}

Feminino Masculino

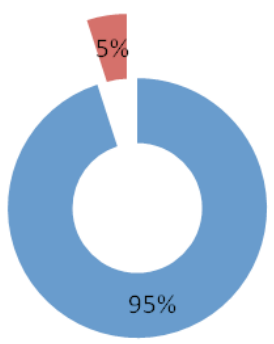

Fonte: Dados da autora.

Para Sforni (2005), a feminização do corpo docente aconteceu, de forma não aleatória. No momento de implantação das primeiras escolas primárias, ao fim do século XIX e início do XX, buscava-se implementar uma escola para a instrução do povo, como também para ordem e moral cívica. Nessa conjuntura, a muIher foi incumbida de modelar os cérebros infantis, a partir de uma habilidade tipicamente feminina: intuição, benevolência e afetividade.

No momento em que as virtudes cívicas ou morais necessárias à preservação das instituições são priorizadas no processo educativo, abrem-se espaços para a mulher. 0 desenvolvimento das virtudes sociais, que passa necessariamente pela educação da vontade, tem no aspecto psicológico um dos principais pontos de atuação. Questão que reforça ainda mais a vinculação entre mulher e ensino. Acredita-se que ela detém o conhecimento da 'alma infantil', um conhecimento prático, adquirido junto ao berço, enquanto mãe. (SFORNI, 2005, p. 321).

Godinho e outros autores (2005), ao analisarem a trajetória da mulher na educação brasileira, des- 
tacaram que ingressar no magistério possibilitou às mulheres de classe média entrar no mercado de trabalho, exercendo um ofício de prestígio social. Além disso, era uma possibilidade de conciliar o trabalho doméstico com os afazeres profissionais, logo, aliava-se a formação de profissionais dedicadas à formação moral do indivíduo, sem oferecer riscos sociais. Podemos considerar que esses fatores ainda não foram superados ao observamos que $95 \%$ do corpo docente no trabalho com a educação especial é do sexo feminino.

Quanto à distribuição da classe docente por faixa etária a pesquisa identificou que, grande parte dos professores, cerca de 85\%, está na faixa de 31-50 anos.

Gráfico II - Distribuição da classe docente por faixa etária - Região Norte
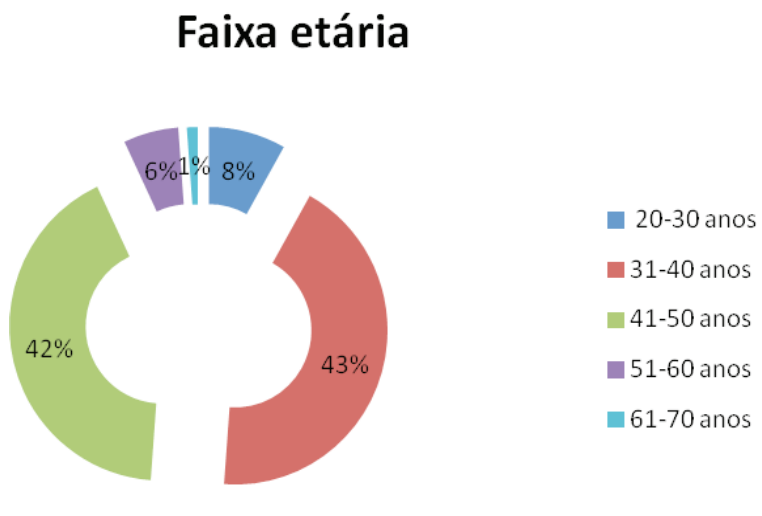

Fonte: Dados da autora.

Compreende-se que, os professores que estão em contato direto com os alunos especiais encontram-se em um momento de estabilização profissional, bem como alta experiência profissional. Esse é um fator positivo para o trabalho de ensino, aprendizagem e desenvolvimento desses educandos.

Sobre a distribuição da classe docente por graduação, investigamos que a graduação de Pedagogia predomina nessa modalidade de ensino. 0 licenciado neste curso, de forma geral, possui habilitação para o trabalho com a Educação Especial. Acreditamos que, com o impulso das políticas de inclusão, o trabalho com alunos especiais passa a ser um campo promissor, fatores que determinam os $70 \%$ dos pesquisadores indicarem a licenciatura de Pedagogia como primeira formação. A segunda licenciatura é Letras com $5 \%$. Na sequência, formados em outra graduação temos $20 \%$, e somente $5 \%$ não responderam.

Gráfico III - Distribuição da classe docente por graduação inicial - Região Norte

\section{Formação/Graduação}

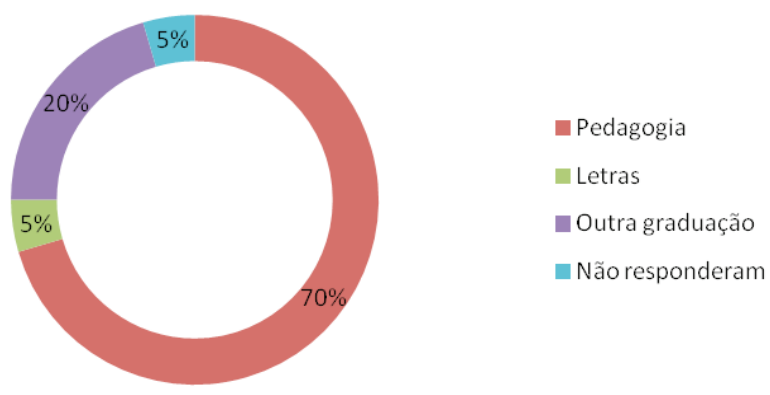

Fonte: Dados da autora.

0 alto número de pedagogos é resultado da Portaria $\mathrm{n}^{0} 1.793$, de dezembro de 1994, do governo federal, que visa a necessidade de complementar os currículos de formação de docentes e outros profissionais que interagem com portadores de necessidades especiais, recomendando em seu Artigo $1^{\circ}$, a inclusão da disciplina "Aspectos ético-político educacionais da normalização e integração da pessoa portadora de necessidades especiais", prioritariamente, nos cursos de Pedagogia, Psicologia e em todas as Licenciaturas.

Além disso, a formação em cursos de licenciaturas é uma das determinações expressas no Artigo 18 da Resolução CNE/CEB n 2, de 11 de setembro de 
2001. Em seu parágrafo $3^{\circ}$ define que os professores especializados em educação especial deverão comprovar formação mínima em cursos de licenciatura em educação especial, ou em uma de suas áreas, preferencialmente de modo concomitante e associado à licenciatura para educação infantil ou para os anos iniciais do ensino fundamental. Além disso, estabelece a complementação de estudos ou pós-graduação em áreas específicas da educação especial, posterior à licenciatura nas diferentes áreas de conhecimento, para atuação nos anos finais do ensino fundamental e no ensino médio.

Com os dados observamos que os professores investigados estão em conformidade com as exigências jurídicas e habilitados para o trabalho educacional solicitado.

Quanto à distribuição da classe docente em nível de pós-graduação, observamos que a busca pela especialização é recente, devido à facilidade de acesso a esse setor e, sem dúvida, devido à competitividade no campo, à medida que nos últimos anos os professores procuram cada vez mais qualificar seu trabalho e currículo. Assim, a pesquisa revela que $38 \%$ estão realizando sua primeira pós-graduação lato sensu em Educação Especial. Aproximadamente $21 \%$ possuem a especialização em Orientação e Gestão escolar, outros $21 \%$ em outras não mencionadas, $9 \%$ já possuem Educação Especial, $7 \%$ em Psicopedagogia e apenas $4 \%$ especializados em Educação Infantil.
Gráfico IV - Distribuição da classe docente por pós-graduação já concluída - Região Norte

\section{Pós Graduação}

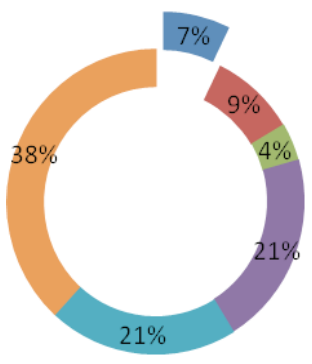

\author{
- Psicopedagogia \\ Ed. Especial \\ Ed. Infantil \\ — Orientação e Gestão \\ Educacional \\ Outras
}

não possuem

Fonte: Dados da autora.

Dentre os fatores que facilitaram o acesso está o incentivo governamental. O Artigo 18, da Resolução CNE/CEB n² 2, de 11 de setembro de 2001, assegura, que aos professores que já estavam exercendo o magistério deveriam ser oferecidas oportunidades de formação continuada, inclusive em nível de especialização, pelas instâncias educacionais da União, dos Estados, do Distrito Federal e dos Municípios. Essa qualificação docente é indispensável, pois de acordo com o Artigo 8 da mesma Resolução, a rede regular de ensino deve prever e prover na organização de suas classes comuns, professores das classes comuns e da educação especial, capacitados e especializados para o atendimento às necessidades educacionais dos alunos.

Sobre a distribuição da classe docente por dependência administrativa, identificou-se que os professores estão, em sua maior proporção, na rede municipal de ensino. Acreditamos que um explicativo seja a política de municipalização da Educação Infantil e Ensino Fundamental. Esses dois níveis de ensino são os maiores receptores de alunos especiais, sabe-se que o número de alunos que alcançam o Ensino Médio 
ainda é pequeno. Vale apontar, também, que tanto na modalidade Fundamental, quanto no Médio, o número de alunos que finalizam o ciclo escolar vem aumentando com a estabilização das políticas inclusivas².

Quanto à distribuição da classe docente por local de atuação, podemos verificar que o acesso e incentivo para qualificação docente foi um impulso para o professor regular buscar sua especialização na área da Educação Especial.

Gráfico V - Distribuição da classe docente por local de atuação - Região Norte

\section{Local de atuação profissional}

- Sala Regular Equipe pedagógica Sala de Recursos Multifuncionais

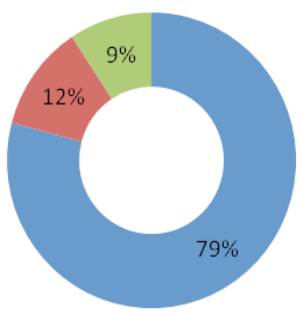

Fonte: Dados da autora.

Dos entrevistados, da região Norte, aproximadamente $79 \%$, atuam nas salas regulares que possuem alunos com NEE, $12 \%$ estão nas equipes pedagógicas, realizando o suporte pedagógico aos educadores e $9 \%$ exercem estritamente nas salas de recursos multifuncionais.

Quanto às escolas públicas que possuem o $\mathrm{AEE}$, o questionário nos mostrou que na região Norte $25 \%$

2. Nosella (2009) compreende que, infelizmente, diante de tal crescimento, a preocupação da sociedade neoliberal é tão somente em "acomodar" socialmente tamanha demanda de jovens em busca de formação. Inclusive, esperam tirar proveito material dessa mão de obra juvenil e, portanto, pensam em profissionalizá-la rápida e precocemente. Fazem assim, diariamente a apologia do ensino técnico e profissionalizante. das instituições escolares que atuam, prioritariamente, com alunos especiais ainda não possuem o AEE.

Gráfico VI - Distribuição de escolas públicas que possuem o serviço do AEE - Região Norte

\section{Atendimento Educacional Especializado}

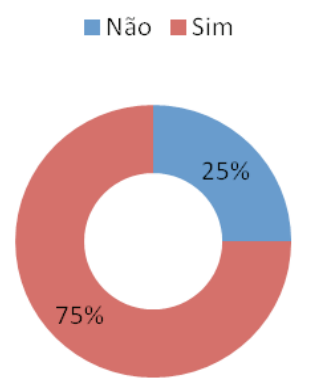

Fonte: Dados da autora.

Sobre a distribuição de escolas públicas que possuem a estrutura de atendimento do $\mathrm{AEE}$, um resultado que nos surpreendeu é que, em contrapartida, $75 \%$ atuam com o suporte do AEE, fator que determina o bom andamento do processo de inclusão escolar. 
Gráfico VII - Distribuição da classe docente por dependência administrativa - Região Norte

\section{Dependência Administrativa}

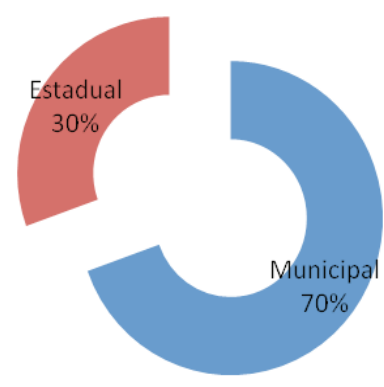

Fonte: Dados da autora.

Consideramos que o avanço das estatísticas sobre a conclusão de alunos com NEE no ensino médio, tem se fortalecido por mudanças legais que fortalecem as políticas públicas de ingresso da pessoa especial ao mercado de trabalho. Diante de uma sociedade mercadológica, incentiva-se o que esse aluno adquira, além do diploma de conclusão, uma habilidade que lhe conferirá o ingresso no mundo do trabalho.

Em meio a uma sociedade voltada à inclusão social, encontram-se as pessoas com deficiência inseridas no trabalho, e isto se impulsionou com a colaboração de algumas normativas vigentes, tais como a Lei $n^{0} 7853 / 89$, que assegura o apoio à integração das pessoas com NEE nas áreas de educação, saúde, formação profissional e trabalho, recursos humanos e edificações.

Assim como, a Lei no 8112/90 que assegurara o direito a vagas desses sujeitos em concursos públicos e Lei no 8213/91, que dispõe sobre a reserva de vagas, obrigatoriamente, em empresas de grande porte. Para empresas com um total de 100 a 200 funcionários, $2 \%$ das vagas devem ser preenchidas por pessoa com deficiência, destinação de $3 \%$ para um total de
201 a 500 funcionários, 4\% de 501 a 1000 e 5\% para empresas com mais de 1000 empregados (DAMBROS ET AL., 2011).

Concluímos que os dados demonstrados permitiram mapearmos, de forma geral, o perfil dos professores que estão atendendo os alunos com NEE, além da extensão do atendimento educacional especializado na região Norte do Brasil.

\section{CONSIDERACÕ̃ES FINAIS}

Essa pesquisa representa um levantamento teórico-prático que não se esgota nas páginas que compõe nosso trabalho, mas acende a novos estudos sobre a educação inclusiva no Brasil e nas regiões investigadas do Norte do país. Em meio aos estudos, coletas de dados, dificuldades de acesso aos documentos, frisamos que nos deparamos com lutas já conquistadas na Educação Especial.

A finalização desse trabalho nos leva a acreditar que os estudos que envolvem o tema Educação Especial buscam fortalecer a defesa de uma modalidade de ensino, que perpasse todos os níveis da educação, incluindo os alunos com NEE no campo escolar. Em nossa concepção, há um caminho ainda a ser trilhado, o de uma inclusão qualitativa, que agregue além da garantia ao acesso às salas regulares, permita também, a promoção de práticas pedagógicas científicas planejadas por educadores capacitados.

O debate sobre a questão da Educação Inclusiva é hoje um fenômeno ambíguo, ao mesmo tempo em que consiste no direito universal e filosoficamente adequado é, também, uma política internacional de organismos financeiros. Para Mendes (2010), não há como questionar a inclusão nem na perspectiva filosófica nem política, pois de fato se trata de uma estratégia com potencial para garantir o avanço necessário na educação especial brasileira. 
Observamos que esse avanço não acompanhou, em muitos casos, a qualidade de ensino nas escolas inclusivas. Permanece, ainda, a visão de uma educação para a satisfação das necessidades básicas de aprendizagem, visão essa oriunda do neoliberalismo. Prioriza-se o desenvolvimento de atitudes, valores e habilidades sociais e, especificamente, para a educação de alunos com NEE, muitas vezes, o atendimento não se desvincula de uma postura assistencial. De forma geral, tanto a educação especial, quanto o ensino regular se encontram na posição de secundarizar a ciência e a apropriação conceitual. Salvo iniciativas isoladas e precursoras que podem ser constatas no atendimento educacional de alunos ao longo da história brasileira.

Acreditamos que diante da hegemonia do capital e de desigualdade posta, a educação deve atuar na instrumentalização científica para essa classe minoritária. Esse reforço é imprescindível, para que a escola não minimize suas ações a conhecimentos espontâneos. Mas, que possuam intrinsecamente a preocupação com a transmissão do conhecimento sistematizado, de caráter científico, com intuito maior de não se distanciar de uma prática humanizadora, isto é, de uma ação docente que conceba a cultura científica como um instrumento simbólico que vise à promoção do desenvolvimento humano.

Destacamos a importância de entendermos que a psicologia histórico-cultural direciona para uma prática educativa, na qual a escola tem papel essencial no desenvolvimento do indivíduo, uma vez que prioriza a apropriação do conhecimento historicamente acumulado.

No processo ensino-aprendizagem é essencial que o professor conheça o nível de desenvolvimento potencial do seu aluno, organizando a sua prática pedagógica com vistas ao desenvolvimento do uso de recursos mediadores pela criança com deficiência.
Vygotsky (1997) já destacava que a diferença básica entre a educação da criança normal e a criança com deficiência, apresenta-se na utilização dos recursos mediadores para o desenvolvimento das funções psicológicas superiores. Em outras palavras, se aluno com NEE não for estimulado por meio de um bom ensino, não consegue usar esses recursos. 0 autor destaca que a educação possibilita o desenvolvimento do homem social, cumprindo a sua função de socialização dos bens culturais e de humanização dos seus alunos, sejam eles com NEE ou não.

A mediação do professor é indispensável nesse processo de mediação, uma vez que o aluno com NEE não se apropria da cultura, apenas por estar inserido em ambientes de ensino, mas por alcançar mediações que tornem a apropriação do conhecimento uma ação conscientizada.

A partir do pressuposto Vygotskyano, defendemos que a educação não se transforme em um local que forme sujeitos ajustados, sem a preocupação com a formação humana, almejamos uma educação para a vida e, que nessa o sujeito possa se emancipar e não se ajustar a máquina social. Uma escola em que todos os seus educandos, sejam eles "especiais" ou não, tenham acesso à ciência, ao conhecimento clássico, ao saber sistematizado, como instrumentos mediadores para passar do conhecimento espontâneo ou cotidiano ao conhecimento científico ou não cotidiano.

Se considerarmos a história e os movimentos de luta pela igualdade de educação para todos, afirmamos que um grande passo já foi consolidado, a garantia de que todos os alunos com NEE tenham acesso a um ambiente escolar. 0 desafio que nos instiga agora é garantir que a escola torna-se um espaço culturalizado, onde nossos alunos tenham a possibilidade de compensar suas dificuldades e desenvolver suas funções psicológicas superiores. Desta forma, somente uma instrução formal oferecida ao nosso aluno especial será capaz de alçar estruturas para sua aprendizagem conceitual. 
Concluímos que em meio a tantos desafios, estados, secretarias, escolas e profissionais da educação voltaram suas ações para compreender o aluno especial como um estudante regular, bem como garantir sua permanência na escola. Sem dúvida essa é a grande vitória para essa modalidade, pois décadas atrás consistia em uma sala de aula desagregada da vida diária de uma escola pública regular.

\section{REFERÊNCIAS}

ALVES-MAZZOTTI, A.J; GEWANDSZNAJDER, F. 0 método nas ciências naturais e sociais: pesquisa quantitativa e qualititativa. São Paulo: Pioneira Thomson Learning, 2002.

CHIZZOTTI, A. Pesquisa em ciências humanas e sociais. 4.ed. São Paulo: Cortez, 2000.

DAMBROS, A. R. T ; NETO, D.G ; SIERRA, D. B ; MORI, N. N. R . A educação profissional de nível médio no Paraná e a inserção da pessoa com deficiência no mundo do trabalho: reflexões acerca da formação mercadológica. In: Congresso Brasileiro Multidisciplinar de Educação Especial. Anais. Londrina: UEL, 2011, 1-11.

GODINHO, T. et al. Trajetória da mulher na educação brasileira 1996-2003. Brasília: Instituto de Pesquisas Educacionais Anísio Teixeira, 2005.
GOULART, A. M. P. L; MORI, N. N. R. A investigação do processo de leitura e escrita sob a perspectiva histórico-cultural. In: MACIEL, L.S.B; MORI, N.N.R.(Orgs). Pesquisas em Educação: Múltiplos olhares. Maringá: EDUEM, 2009.

LEONTIEV, A.N. O desenvolvimento do psiquismo. Lisboa: Livros Horizonte, 1979.

MENDES, E. G. A radicalização do debate sobre a inclusão escolar no Brasil. Revista Brasileira de Educação, v.11. n.33, 2006.

NOSELLA, P. Ensino Médio: em busca do principio pedagógico. VI Colóquio de Pesquisa sobre Instituições Escolares - LIPHIS do PPGE da UNINOVE-SP, 2008.

SFORNI, Marta Sueli. Escola pública e feminização docente: da instrução à educação. Revista de Teoria e prática da Educação, v.8, n.3, Maringá, set/dez. 2005.

VYGOTSKY, L.S. A construção do pensamento e da linguagem. Tradução Paulo Bezerra. 2.ed. São Paulo: Martins Fontes, 2009.

VYGOTSKY, L.S. Obras Escogidas V Fundamentos da defectologia. Madrid: Visor Distribuciones,1997. 
